\title{
Depression and Increased Mortality in Diabetes: Unexpected Causes of Death
}

\author{
Elizabeth H. B. Lin, MD, MPH \\ Susan R. Heckbert, MD, Pb. $D^{1,2}$ \\ Carolyn M. Rutter, PbD \\ Wayne J. Katon, $M D^{3}$ \\ Paul Ciechanowski, $M D, M P H^{3}$ \\ Evette J. Ludman, $P b D^{1}$ \\ Malia Oliver, $B A^{1}$ \\ Bessie A. Young, MD, MPH \\ David K. McCulloch, MD \\ Michael Von Korff, ScD 1 \\ 'Group Health Research Institute, Seattle, \\ Washington \\ ${ }^{2}$ Cardiovascular Health Research Unit, \\ Department of Epidemiology, School of \\ Public Health and Community Medi- \\ cine, University of Washington, Seattle, \\ Washington \\ ${ }^{3}$ Department of Psychiatry and Behavioral \\ Sciences, University of Washington School \\ of Medicine, Seattle, Washington \\ ${ }^{4}$ Epidemiologic Research and Information \\ Center, VA Puget Sound Health Care Sys- \\ tem, University of Washington School of \\ Medicine, Seattle, Washington
}

Conflicts of interest: none reported

\section{CORRESPONDING AUTHOR}

Elizabeth H. B. Lin, MD, MPH

Group Health Research Institute

1730 Minor Ave, Suite 1600

Seattle, WA 98101

lin.e@ghc.org

\begin{abstract}
PURPOSE Recent evidence suggests that depression is linked to increased mortality among patients with diabetes. This study examines the association of depression with all-cause and cause-specific mortality in diabetes.
\end{abstract}

METHODS We conducted a prospective cohort study of primary care patients with type 2 diabetes at Group Health Cooperative in Washington state. We used the Patient Health Questionnaire (PHQ-9) to assess depression at baseline and reviewed medical records supplemented by the Washington state mortality registry to ascertain the causes of death.

RESULTS Among a cohort of 4,184 patients, 581 patients died during the follow-up period. Deaths occurred among 428 (12.9\%) patients with no depression, among 88 (17.8\%) patients with major depression, and among 65 (18.2\%) patients with minor depression. Causes of death were grouped as cardiovascular disease, $42.7 \%$; cancer, $26.9 \%$; and deaths that were not due to cardiovascular disease or cancer, 30.5\%. Infections, dementia, renal failure, and chronic obstructive pulmonary disease were the most frequent causes in the latter group. Adjusting for demographic characteristics, baseline major depression (relative to no depression) was significantly associated with all-cause mortality (hazard ratio $[\mathrm{HR}]=2.26,95 \%$ confidence interval $[\mathrm{Cl}], 1.79-2.85)$, with cardiovascular mortality ( $\mathrm{HR}=2.00 ; 95 \% \mathrm{Cl}, 1.37-2.94)$, and with noncardiovascular, noncancer mortality ( $\mathrm{HR}=3.35 ; 95 \% \mathrm{Cl}, 2.30-4.89$ ). After additional adjustment for baseline clinical characteristics and health habits, major depression was significantly associated only with all-cause mortality ( $\mathrm{HR}=1.52 ; 95 \% \mathrm{Cl}, 1.19-1.95)$ and with death not caused by cancer or atherosclerotic cardiovascular disease $(\mathrm{HR}=2.15 ; 95 \% \mathrm{Cl}$, 1.43-3.24). Minor depression showed similar but nonsignificant associations.

CONCLUSIONS Patients with diabetes and coexisting depression face substantially elevated mortality risks beyond cardiovascular deaths.

Ann Fam Med 2009:7:414-421. doi:10.1370/afm.998.

\section{INTRODUCTION}

E pidemiologic studies conducted in both community and medical settings find that people with diabetes are more likely than others to experience depression. ${ }^{1}$ Depression affects about 20\% to $25 \%$ of patients with diabetes, nearly twice as many as in the general medical population. ${ }^{2,3}$ Recent evidence suggests that patients with diabetes and coexisting depression have higher all-cause mortality relative to diabetes patients with no depression. ${ }^{4-8}$ Prior studies, however, have not examined how depression influences cause-specific mortality among patients with diabetes.

From incidence to complications and mortality, depression is linked to adverse health effects of diabetes. Depression-diabetes comorbidity is characterized by younger age of diabetes onset; ${ }_{i}$ poor management of diet, exercise, and medications; less favorable glycemic control; and higher risk of complications..$^{911}$ End-organ damage resulting from macrovascular and microvascular complications are believed to be common causes of death among persons with diabetes, with ischemic heart disease the most 
common underlying cause of death. ${ }^{12,13}$ Examining cause-specific mortality may shed light on possible mechanisms through which depression increases risks of dying and may be a first step toward identifying potentially modifiable risk factors among patients with diabetes and coexisting depression.

Since epidemiologic research first linked depression with increased mortality after myocardial infarction, ${ }^{14}$ most research on depression and mortality has focused on cardiovascular disease. ${ }^{15}$ Hypothesized mechanisms include biologic, behavioral, genetic, and social factors ranging from inflammatory factors (eg, C-reactive protein) to physical inactivity and lack of social support. ${ }^{16}$ Our study examines the association of depression with all-cause and cause-specific mortality among persons with diabetes and is part of a larger epidemiologic and intervention study among primary care patients with diabetes (The Pathways Epidemiologic Follow-up Study).,17 We sought to determine whether depression was associated mainly with mortality caused by cardiovascular disease or was also associated with increased risks of death from other common medical causes.

\section{METHODS}

\section{Setting}

Group Health Cooperative is a mixed-model prepaid health plan serving approximately 500,000 members in Washington state. Most Group Health members receive diabetes and medical services within the integrated group practice, which includes 30 primary care clinics in Western Washington. The Group Health enrollment is demographically similar to the area population. Nine primary care clinics were selected for (1) the largest numbers of patients with diabetes, (2) geographic proximity to Seattle, and (3) racial and ethnic diversity. Mean age was slightly higher in the selected clinics (48.8 years vs 47.4 years in all Group Health clinics), and sex distribution was nearly identical (54.7\% women vs $54.5 \%$ men) compared with the other 21 Group Health primary care clinics. All study procedures were approved by institutional review boards at Group Health and the University of Washington.

\section{Study Cohort Selection}

The cohort for the longitudinal survey, the Pathways Study, was drawn from adults in the Group Health diabetes registry who received care at any of the 9 primary care clinics between 2000 and 2002. ${ }^{3}$ The diabetes registry includes all Group Health members meeting any of the following eligibility criteria in the preceding 12 months: filled prescription for insulin or an oral hypoglycemic agent, 2 fasting plasma glucose levels of $126 \mathrm{mg} / \mathrm{dL}$ or greater in a 12 -month period, 2 random plasma glucose levels of $200 \mathrm{mg} / \mathrm{dL}$ or greater in a 12 -month period, 2 outpatient diagnoses of diabetes, or any inpatient diagnosis of diabetes. Beginning in March 2001, questionnaires were mailed to 9,064 potentially eligible patients, but 1,223 patients were later found to be ineligible because of such reasons as death, disenrollment, erroneous diagnosis of diabetes, or cognitive impairment (Figure 1). Among the 7,841 eligible patients, 4,839 (61.7\% of eligible patients) returned the baseline questionnaire.

Overall, nonresponders were less likely to be on antidepressants (23\% vs $26 \%$ for responders), were less likely to be on insulin (25\% vs $30 \%$ ), were less likely to be on the Group Health heart care registry (40\% vs $52 \%)$, had fewer primary care visits in the year before the survey or survey attempt (mean 5.1 vs 6.0), had fewer specialty care visits in the previous year (mean 2.8 vs 3.5 ), were younger (mean age 58.9 vs 64.6 years), and were less likely to have had a recent glycated hemoglobin $\left(\mathrm{HbA}_{1 \mathrm{c})}\right.$ measurement $(86.1 \%$ vs 97.5\%). Of those with $\mathrm{HbA}_{1 \mathrm{c}}$ results in the previous year, nonresponders were more likely to have a blood glucose level that exceeded $8 \%$ (50\% vs $37 \%$ ). Nonresponders also had a lower comorbidity score (RxRisk) than responders (mean 2,873 vs 3,490 ). Patients with type 1 or unknown type of diabetes $(n=216)$ were excluded. A total of 4,623 patients with type 2 diabetes participated in the study and comprised the original Pathways Epidemiologic Study cohort. ${ }^{3}$

\section{Pathways Epidemiologic Follow-Up Study}

Approximately 5 years after enrollment, surviving members of the cohort of 4,623 diabetes patients were contacted again by a mailed letter and follow-up telephone call between 2005 and 2007. Consenting patients completed a 20-minute telephone interview and were asked for permission to review their electronic and paper medical records for information on medical conditions. Waiver of consent for medical record review was approved by the Human Subjects Review Committee for patients who had died since enrollment in the cohort.

\section{Measures}

Depression at baseline was assessed using the Patient Health Questionnaire-9 (PHQ-9), ${ }^{18}$ a self-report measure of depression symptoms based on the American Psychiatric Association's Diagnostic and Statistical Manual of Mental Disorders (Fourth Edition) ${ }^{19}$ criteria for diagnosis of depressive episode. The PHQ-9 has been found to have an adequate sensitivity and high specificity in relation to a diagnosis of major depression based on structured interviews. ${ }^{20}$ Each item was scored as positive if endorsed "more than half the time" or "nearly all 
the time." A diagnosis of major depression required a positive response to 1 of the 2 core symptoms (depressed mood or loss of interest) and a total of 5 positive symptoms for at least the last 2 weeks. Criteria for minor depression were at least 1 core symptom (depressed mood or loss of interest) and a total of 2 to 4 positive symptoms for at least the last 2 weeks.

The mailed questionnaire elicited information on sociodemographic characteristics (age, sex, race, educational attainment, and employment), diabetes duration, diabetes treatment (none or diet, oral hypoglycemic only, insulin with or without an oral hypoglycemic), height, weight, and health risk behaviors (smoking, physical activity [exercise $1 \mathrm{~d} /$ wk or more]). Medical record review and automated laboratory data provided information on physician diagnosis of hypertension, body mass index at baseline, and $\mathrm{HbA}_{1 \mathrm{c}}$ levels during the 12 months before baseline. Computerized pharmacy records were used to compute the RxRisk score, a measure of medical comorbidity that has been found to predict mortality and health care costs. ${ }^{21,22}$ The numerical score indicates predicted health services costs for the next 6 months. For this study, antidepressant and hypoglycemic medications were not included in the calculation of the RxRisk score. This modified RxRisk score should be considered a measure of overall medical comorbidity other than depression or diabetes.

\section{Mortality, Cause of Death}

Each year, Group Health conducts a computerized match between its enrollment files and the death registry files of Washington state. Each participant's vital status was checked using this information before conducting the follow-up mailing and telephone survey. Several additional deaths were ascertained at the time of telephone survey. The underlying cause of death was classified on the basis of review of inpatient and outpatient medical records just preceding the death, the death certificate, and other records, such
Figure 1. Recruitment of epidemiologic cohort study to assess mortality.

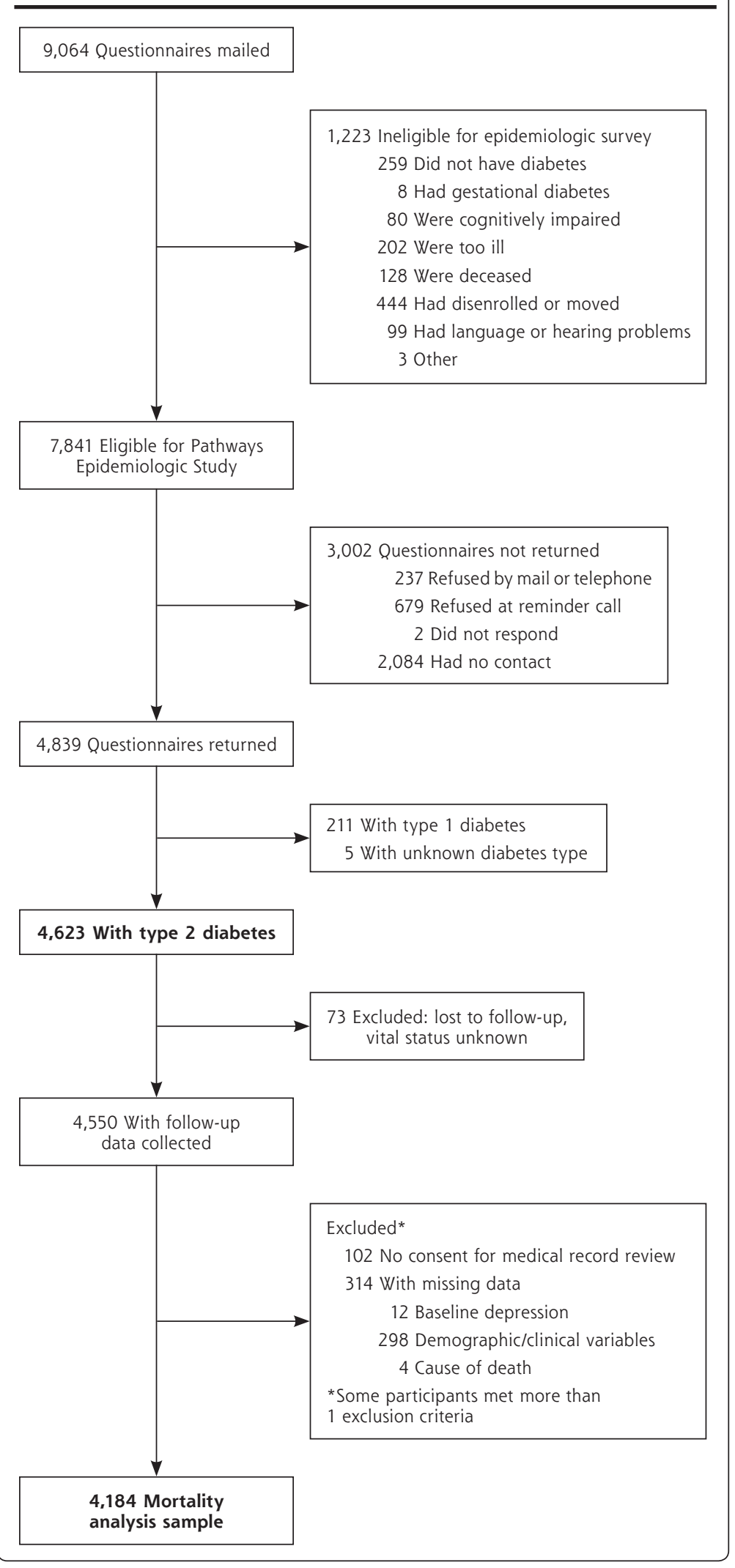


as an autopsy report, using the methods developed in the Women's Health Initiative, ${ }^{22}$ with researchers blinded to information on depression status and cohort entry date. ${ }^{23}$ Evidence documented on recent hospitalization, outpatient visits, and autopsy records was considered the most reliable for determining cause of death. The death certificate diagnosis was used when no other records were available. Two physicians (S.H. and E.H.B.L.) reviewed all deaths and determined the underlying cause of death by consensus. Mortality caused by atherosclerotic cardiovascular disease included deaths caused by coronary artery disease, ischemic stroke, or peripheral vascular disease. Strokes were assumed to be ischemic if there was no International Classification of Disease, Ninth Revision (ICD-9) code indicating hemorrhagic stroke. Heart disease deaths that were not due to coronary disease, such as deaths resulting from valvular heart disease, were classified as cardiac, noncoronary deaths and were not included in the cardiovascular disease category.

\section{Statistical Analyses}

Causes of death were divided into 3 groups: (1) cardiovascular disease mortality, (2) cancer mortality, and (3) noncardiovascular, noncancer mortality. The latter group included infection, dementia, renal failure, chronic obstructive pulmonary disease, and other causes. Each cause occurred too infrequently to support cause-specific analyses, and these causes of death were therefore combined as the noncardiovascular, noncancer mortality group.

We estimated the association between depression and mortality using a proportional hazards model. We fit 3 proportional hazards models to each mortality outcome, with each sequential model including additional covariates. The first model included baseline depression (major, minor, none) adjusted for demographic characteristics (age, sex, race, education, and marital status). The second model added clinical characteristics at baseline (diabetes duration, type of treatment, medical comorbidity, and hypertension diagnosis). The third model added baseline health habits and disease control measures that may be affected by depression $\left(\mathrm{HbA}_{1 \mathrm{c}}\right.$, body mass index, smoking, and limited physical activity). We examined the proportional hazards assumption using Schoenfeld residuals as described by Therneau and Grambsch. ${ }^{24}$

Time to death was censored at disenrollment from the health plan. Cause-specific analyses censored individuals at the time of other-cause event. When there are competing risks, this type of censoring can bias estimated associations. ${ }^{25}$ For example, if individuals who die from cancer are also more likely to die of cardiovascular disease, then censoring individuals at cancer death removes individuals at higher risk for cardiovascular disease from the analysis, so that the remaining individuals are at lower risk for cardiovascular death than would be expected with a random censoring process. We used sensitivity analyses to examine the potential impact of competing risks on estimates of the association between depression and cause-specific mortality outcomes. In a second set of analyses, we used a cumulative incidence approach, censoring individuals only at disenrollment, keeping those with deaths from other causes in the risk set. There were no meaningful differences in the estimated association between depression and cause-specific mortality under these 2 censoring mechanisms, suggesting that competing risks did not bias estimated effects of depression. We present results only for the cause-specific models that censor individuals at the time of other-cause events.

\section{RESULTS}

Figure 1 displays the Pathways Epidemiologic and Follow-Up Study sample recruitment. Among 4,623 patients with type 2 diabetes surveyed at baseline, 73 (1.6\%) were lost to follow-up and vital status could not be determined. Follow-up data were collected on a total of 4,550 patients, of whom 102 (2.2\%) did not give permission for review of medical record data. Data were missing on depression status $(n=12), 1$ or more demographic or clinical variables $(n=298)$, or cause of death $(n=14)$, leaving a final sample size of 4,184 patients for analysis. The duration of follow-up was nearly 5 years ( mean $=4.4$ years; SD, 1.5 years).

Clinical and demographic characteristics of the Pathways cohort by baseline depression status are summarized in Table 1 . As reported previously, diabetes patients with major depression were more likely to be women, slightly younger, and receiving insulin treatment, and they had higher $\mathrm{HbA}_{1 \mathrm{c}}$ levels and more medical comorbidities. Patients with major depression also reported more health-risk behaviors, such as physical inactivity and smoking. ${ }^{3}$ There were 428 (12.8\%) deaths in 3,334 patients without depression, 65 (18.2\%) deaths in 357 patients with minor depression, and 88 (17.9\%) deaths in 493 patients with major depression. Cause of death was atherosclerotic cardiovascular disease in $42.7 \%$, cancer in $26.9 \%$, a noncardiovascular or noncancer cause in $30.5 \%$ (Table 2).

Table 3 displays the model-based hazard ratios for the mortality groups, comparing baseline depression status relative to the no depression group. Major depression was associated with both all-cause and noncardiovascular, noncancer-related mortality for all alternative regression models. The strength of asso- 
Table 1. Baseline Clinical and Demographic Characteristics by Depression

\begin{tabular}{|c|c|c|c|c|}
\hline Variable & Total & No Depression & $\begin{array}{c}\text { Minor } \\
\text { Depression }\end{array}$ & $\begin{array}{c}\text { Major } \\
\text { Depression }\end{array}$ \\
\hline Number & 4,184 & $3,334(79.7)$ & $357(8.5)$ & $493(11.8)$ \\
\hline Age, mean (SD), years & $64.0(12.5)$ & $64.7(12.2)$ & $64.5(13.2)$ & $59.6(12.8)$ \\
\hline Female, n (\%) & $2,030(48.5)$ & $1,564(46.9)$ & $180(50.4)$ & $286(58.0)$ \\
\hline Nonwhite, $\mathrm{n}(\%)$ & $879(21.0)$ & $679(20.4)$ & $95(26.6)$ & $105(21.3)$ \\
\hline High school or less, $\mathrm{n}(\%)$ & $1,057(25.3)$ & $808(24.2)$ & $113(31.7)$ & $136(27.6)$ \\
\hline Marital status single, $\mathrm{n}(\%)$ & $1,390(33.2)$ & $1,060(31.8)$ & $127(35.6)$ & $203(41.2)$ \\
\hline Diabetes duration, mean (SD), years & $8.6(8.2)$ & $8.5(8.2)$ & $10.0(9.0)$ & $8.8(7.3)$ \\
\hline $\mathrm{HbA}_{1 \mathrm{C}}$, mean (SD), \% & $7.8(1.5)$ & $7.7(1.5)$ & $7.9(1.6)$ & $8.1(1.7)$ \\
\hline \multicolumn{5}{|l|}{ Treatment, n (\%) } \\
\hline None or diet & $1,078(25.8)$ & $913(27.4)$ & $80(22.4)$ & $85(17.2)$ \\
\hline Hypoglycemic only & $1,971(47.1)$ & $1,607(48.2)$ & $161(45.1)$ & $203(41.2)$ \\
\hline Any insulin & $1,135(27.1)$ & $814(24.4)$ & $116(32.5)$ & $205(41.6)$ \\
\hline Hypertension, n (\%) & $2,565(61.3)$ & $2,029(60.9)$ & $231(64.7)$ & $305(61.9)$ \\
\hline Body mass index, mean (SD) & $31.7(7.2)$ & $31.2(6.7)$ & $32.3(7.0)$ & $35.0(9.1)$ \\
\hline Physical activity $1 \mathrm{~d} /$ wk or more, $\mathrm{n}(\%)$ & $1,362(32.6)$ & $969(29.1)$ & $159(44.5)$ & $234(47.5)$ \\
\hline Current smoking, $\mathrm{n}(\%)$ & $362(8.7)$ & $246(7.4)$ & $38(10.6)$ & $78(15.8)$ \\
\hline RXRiska & $3,132(2403)$ & $3,049(2297)$ & $3,383(2472)$ & $3,508(2944)$ \\
\hline
\end{tabular}

ciation between depression and mortality decreased after adjustment for clinical characteristics and, to a lesser extent, potential mediators. Major depression was associated with cardiovascular-related mortality after controlling for demographic variables, but not after controlling for clinical or potentially mediating variables. Risk for cancer-related mortality appeared elevated but the increase did not reach statistical significance. After adjustment for demographic characteristics, clinical characteristics, and health habits, the strongest observed association was between major depression and noncardiovascular, noncancer-related mortality $(\mathrm{HR}=2.15 ; 95 \% \mathrm{CI}, 1.43-3.24)$ followed by the association between major depression and allcause mortality $(\mathrm{HR}=1.52 ; 95 \% \mathrm{CI}, 1.19-1.95)$. Minor depression and mortality outcomes showed similar associations, but the associations were weaker and were not significant in covariate-adjusted models (Table 3 ).

\section{DISCUSSION}

In the Pathways Epidemiologic Follow-up Study of a primary care cohort of patients with diabetes, we found that atherosclerotic cardiovascular disease and cancer were the 2 leading causes of death. Noncardiovascular and noncancer causes, such as infection, dementia, renal failure, and chronic obstructive pulmonary disease, were less common. Consistent with earlier research, diabetes patients with coexisting depression differed significantly from those with no depression. Depressed patients were more likely to

\begin{tabular}{|lrl|}
\hline Table 2. Cause-Specific Mortality & \\
\hline Cause of Death & No. & \multicolumn{1}{c|}{$\%$} \\
\hline Atherosclerotic cardiovascular disease & 248 & 42.7 \\
Coronary disease & 202 & 34.8 \\
Ischemic stroke & 35 & 6.0 \\
Peripheral vascular disease & 11 & 1.9 \\
Cancer & 156 & 26.9 \\
Lung & 32 & 5.5 \\
Colorectal & 17 & 2.9 \\
Prostate & 12 & 2.1 \\
Breast & 12 & 2.1 \\
Other and unknown primary site & 83 & 14.3 \\
Noncardiovascular, noncancer & 177 & 30.5 \\
Infection & 44 & 7.6 \\
Dementia and other CNS disease & 33 & 5.7 \\
Renal failure & 17 & 2.9 \\
Chronic obstructive pulmonary disease & 27 & 4.6 \\
and other respiratory disease & & \\
Cirrhosis and other gastrointestinal & 18 & 3.1 \\
disease & & \\
Hemorrhagic stroke & 8 & 1.4 \\
Cardiac, noncoronary & 8 & 1.4 \\
Accident & 5 & 0.9 \\
Suicide & 4 & 0.7 \\
Other & 13 & 2.2 \\
Total & 581 & 100.0 \\
\hline CNs = central nervous system. & & \\
\hline
\end{tabular}

be single women and slightly younger, but they had longer duration of diabetes, less-healthful habits, worse glycemic control, and more medical comorbidities. After adjustment for demographic and clinical char- 


\begin{tabular}{|c|c|c|c|c|}
\hline \multirow[b]{2}{*}{ Baseline and Adjusted Models } & \multicolumn{4}{|c|}{ Cause of Death } \\
\hline & All-Cause & Cardiovascular & Cancer & $\begin{array}{l}\text { Noncardiovascular, } \\
\text { Noncancer }\end{array}$ \\
\hline \multicolumn{5}{|l|}{ Events, No. (\%) } \\
\hline Not depressed & $428(12.8)$ & $187(5.6)$ & $123(3.7)$ & $118(3.5)$ \\
\hline Minor depression & $65(18.2)$ & $29(8.1)$ & $13(3.6)$ & $23(6.4)$ \\
\hline Major depression & $88(17.8)$ & $32(6.5)$ & $20(4.1)$ & $36(7.3)$ \\
\hline \multicolumn{5}{|c|}{$\begin{array}{l}\text { Adjusted for demographic characteristics, }{ }^{a} \\
\operatorname{HR}(95 \% \mathrm{Cl})\end{array}$} \\
\hline Minor depression & $1.48(1.14-1.93)$ & $1.51(1.02-2.24)$ & $1.04(0.59-1.85)$ & $1.87(1.19-2.93)$ \\
\hline Major depression & $2.26(1.79-2.85)$ & $2.00(1.37-2.94)$ & $1.61(0.99-2.59)$ & $3.35(2.30-4.89)$ \\
\hline \multicolumn{5}{|l|}{$\begin{array}{l}\text { Adjusted for demographica and clinical } \\
\text { characteristics, }{ }^{b} \mathrm{HR}(95 \% \mathrm{Cl})\end{array}$} \\
\hline Minor depression & $1.29(0.99-1.68)$ & $1.27(0.86-1.89)$ & $0.99(0.56-1.76)$ & $1.59(1.01-2.49)$ \\
\hline Major depression & $1.62(1.28-2.06)$ & $1.35(0.91-1.99)$ & $1.36(0.83-2.22)$ & $2.26(1.52-3.35)$ \\
\hline \multicolumn{5}{|c|}{$\begin{array}{l}\text { Adjusted for demographic, }{ }^{a} \text { clinical } \\
\text { characteristics, }{ }^{b} \text { health habits and disease } \\
\text { control measures, }{ }^{c} \text { HR }(95 \% \text { Cl) }\end{array}$} \\
\hline Minor depression & $1.24(0.95-1.61)$ & $1.20(0.81-1.78)$ & $0.94(0.53-1.68)$ & $1.54(0.98-2.42)$ \\
\hline Major depression & $1.52(1.19-1.95)$ & $1.25(0.83-1.86)$ & $1.27(0.77-2.10)$ & $2.15(1.43-3.24)$ \\
\hline \multicolumn{5}{|c|}{$\mathrm{Cl}=$ confidence interval; $\mathrm{CVD}=$ cardiovascular disease; $\mathrm{HR}=$ hazards ratio. } \\
\hline \multicolumn{5}{|c|}{$\begin{array}{l}\text { a Demographic characteristics at baseline: age, sex, race, education, and marital status. } \\
\text { bC Clinical characteristics at baseline: diabetes duration, treatment intensity, medical comorbidity (excluding diabetes, depression), and hypertension diagnosis. } \\
\text { 'Health behaviors and disease control measures at baseline: body mass index, smoking, limited physical activity, and glycated hemoglobin. }\end{array}$} \\
\hline
\end{tabular}

acteristics, health risk behaviors, and disease control measures, major depression was significantly associated with all-cause mortality and noncardiovascular, noncancer-related mortality. After adjustment for these same characteristics, minor depression showed a nonsignificant association with any mortality outcome. For both major and minor depression, adjustment for clinical characteristics attenuated the associations with mortality outcomes.

Strengths of this study include the validated diagnosis of diabetes, standardized assessment of depression symptoms based on the DSM-IV criteria for diagnosis of major and minor depression, ${ }_{1}^{18,20}$ inclusion of clinical characteristics and health-risk behaviors (such as severity of coexisting medical conditions and smoking status) in the analytic models, and review of the original medical records and death certificate data that permitted adjudication of the underlying cause of death using validated methods.

Limitations of the present study are that depression was assessed at a single point in time and we did not have information about the history of depression before baseline measurements or interim depression status before death. Lack of information on medication adherence is a limitation of these analyses. Although review of medical records can help overcome inaccuracies in the death certificate coding of cause of death, adjudication of underlying cause of death remains dif- ficult and is subject to error. As with all observational studies, there is the potential for residual confounding, that is, that effects of depression on mortality may be due to another characteristic related to both depression and mortality.

It should be noted that the clinical and lifestyle factors which were adjusted for in the analytic models may include variables through which depression influences mortality rates (mediators such as severity of coexisting medical conditions), as well as factors that independently influence mortality and are also associated with depression (confounders such as physical activity). Our earlier research showed that patients with diabetes and comorbid depression develop diabetes 5 to 6 years earlier than those without depression and have poor self-care, which may influence severity of diabetes. ${ }^{3}$ Also, depression was shown to be associated with such health behaviors as sedentary lifestyle, obesity, and smoking. ${ }^{10}$ It was not possible to completely differentiate the effects of potential mediators and potential confounders on the relationship between major depression and mortality. In the fully-adjusted model, the nonsignificant association of major depression with cardiovascular-related mortality may reflect that the clinical factors and health-risk behaviors controlled for in the analyses included important variables implicated in the relationship between depression and cardiovascular-related mortality (eg, diabetes duration, 
smoking, body mass index and $\mathrm{HbA}_{1 \mathrm{c}}$ ). Higher levels of medical comorbidity and risk factors may in large part result from the presence of depression. Analytic models that adjust for risk factors strongly associated with depression may not accurately reflect the clinical course of depressed patients with diabetes.

This study is the first to examine cause-specific mortality and depression in a diabetes cohort. Our findings suggest that patients with comorbid diabetes and depression face increased mortality risks beyond cardiovascular-related mortality. Emerging epidemiologic results among worldwide populations not limited to patients with diabetes have reported positive links between depression and mortality across a wide spectrum of noncardiovascular causes, including cancer, human immunodeficiency virus, chronic obstructive pulmonary disease, and rheumatoid arthritis. ${ }^{26-29} \mathrm{~A}$ large population-based study in Norway confirmed that depression was a risk factor for all major diseaserelated deaths, not just cardiovascular disease. ${ }^{30}$

A randomized clinical trial among older adults recently showed that improving depression care was associated with lower mortality. ${ }^{31}$ Our study identified potentially modifiable characteristics (eg, severity of coexisting medical disorders, unhealthy lifestyles, and glycemic control) that may be particularly important in cardiovascular-related mortality among persons with diabetes., Controlling for these factors, however, did not fully explain the association between major depression and all-cause mortality. The association of depression with a wide spectrum of mortality causes calls for reexamination of the causal mechanisms underlying the link between depression and excess mortality. These factors are likely to be pervasive and to include both physiologic and behavioral pathways. Obesity, smoking, and physical inactivity are more common among patients with diabetes and depression compared with diabetes patients who do not have depression ${ }_{1}^{10}$ which may help explain the ubiquitous association of depression with a wide array of death causes. Poor adherence to medications among depressed patients also represents another behavioral pathway to higher mortality across illnesses. Physiologic changes evident among depressed patients with cardiovascular disease, such as inflammatory processes, ${ }^{32}$ can also play a role in noncardiovascular mortalities, such as dementia. ${ }^{33}$ The association of depression with changes in neuroendocrine system regulation and immune system function could also increase mortality risks beyond cardiovascular disease. $^{34,35}$ To decrease the mortality burden for patients with comorbid diabetes and depression, studies should examine interventions aimed at improving health behavior, medication adherence, and better control of medical comorbidities, in addition to optimal depression care.
To read or post commentaries in response to this article, see it online at http://www.annfammed.org/cgi/content/full/7/5/414.

Key words: Diabetes; depression; mortality

Submitted November 11, 2008; submitted, revised, February 6, 2009; accepted February 16, 2009.

Funding support: This research was supported by grants from the National Institutes of Health MH 073686.

\section{References}

1. Eaton WW. Epidemiologic evidence on the comorbidity of depression and diabetes. J Psychosom Res. 2002;53(4):903-906.

2. Anderson RJ, Freedland KE, Clouse RE, Lustman PJ. The prevalence of comorbid depression in adults with diabetes: a meta-analysis. Diabetes Care. 2001;24(6):1069-1078.

3. Katon W, von Korff M, Ciechanowski P, et al. Behavioral and clinical factors associated with depression among individuals with diabetes. Diabetes Care. 2004;27(4):914-920.

4. Egede LE, Nietert PJ, Zheng D. Depression and all-cause and coronary heart disease mortality among adults with and without diabetes. Diabetes Care. 2005;28(6):1339-1345.

5. Black SA, Markides KS, Ray LA. Depression predicts increased incidence of adverse health outcomes in older Mexican Americans with type 2 diabetes. Diabetes Care. 2003;26(10):2822-2828.

6. Katon WJ, Rutter C, Simon G, et al. The association of comorbid depression with mortality in patients with type 2 diabetes. Diabetes Care. 2005;28(11):2668-2672.

7. Zhang X, Norris SL, Gregg EW, Cheng YJ, Beckles G, Kahn HS. Depressive symptoms and mortality among persons with and without diabetes. Am J Epidemiol. 2005;161(7):652-660.

8. Ismail K, Winkley K, Stahl D, Chalder T, Edmonds M. A cohort study of people with diabetes and their first foot ulcer: the role of depression on mortality. Diabetes Care. 2007;30(6):1473-1479.

9. Lustman PJ, Anderson RJ, Freedland KE, de Groot M, Carney RM, Clouse RE. Depression and poor glycemic control: a meta-analytic review of the literature. Diabetes Care. 2000;23(7):934-942.

10. Lin EHB, Katon WVKM, Von Korff M, et al. Relationship of depression and diabetes self-care, medication adherence, and preventive care. Diabetes Care. 2004;27(9):2154-2160.

11. de Groot M, Anderson R, Freedland KE, Clouse RE, Lustman PJ. Association of depression and diabetes complications: a meta-analysis. Psychosom Med. 2001;63(4):619-630.

12. Young BA, Lin $E$, Von Korff $M$, et al. Diabetes complications severity index and risk of mortality, hospitalization, and healthcare utilization. Am J Manag Care. 2008;14(1):15-23.

13. Ford ES, DeStefano F. Risk factors for mortality from all causes and from coronary heart disease among persons with diabetes. Findings from the National Health and Nutrition Examination Survey I Epidemiologic Follow-up Study. Am J Epidemiol. 1991;133(12):1220-1230.

14. Frasure-Smith N, Lespérance F, Talajic M. Depression following myocardial infarction. Impact on 6-month survival. JAMA. 1993; 270(15):1819-1825.

15. van Melle JP, de Jonge $P$, Spijkerman TA, et al. Prognostic association of depression following myocardial infarction with mortality and cardiovascular events: a meta-analysis. Psychosom Med. 2004;66(6):814-822.

16. Skala JA, Freedland KE, Carney RM. Coronary heart disease and depression: a review of recent mechanistic research. Can J Psychiatry. 2006;51(12):738-745. 
17. Katon WJ, Von Korff M, Lin EH, et al. The Pathways Study: a randomized trial of collaborative care in patients with diabetes and depression. Arch Gen Psychiatry. 2004;61(10):1042-1049.

18. Spitzer RL, Kroenke K, Williams JB. Validation and utility of a selfreport version of PRIME-MD: the PHQ primary care study. Primary Care Evaluation of Mental Disorders. Patient Health Questionnaire. JAMA. 1999;282(18):1737-1744.

19. Diagnostic and Statistical Manual of Mental Disorders. 4th ed. Washington, DC: American Psychiatric Association; 1994.

20. Kroenke K, Spitzer RL, Williams JB. The PHQ-9: validity of a brief depression severity measure. J Gen Intern Med. 2001;16(9):606-613.

21. Fishman PA, Goodman MJ, Hornbrook MC, Meenan RT, Bachman DJ, O'Keeffe Rosetti MC. Risk adjustment using automated ambulatory pharmacy data: the RxRisk model. Med Care. 2003;41(1):84-99.

22. Clark DO, Von Korff M, Saunders K, Baluch WM, Simon GE. A chronic disease score with empirically derived weights. Med Care. 1995;33(8):783-795.

23. Curb JD, McTiernan A, Heckbert SR, et al.; WHI Morbidity and Mortality Committee. Outcomes ascertainment and adjudication methods in the Women's Health Initiative. Ann Epidemiol. 2003;13(9)(Suppl):S122-S128

24. Therneau TM, Grambsch PM. Modeling Survival Data: Extending the Cox Model. New York, NY: Springer; 2000.

25. Putter H, Fiocco M, Geskus RB. Tutorial in biostatistics: competing risks and multi-state models. Stat Med. 2007;26(11):2389-2430.

26. Ang DC, Choi H, Kroenke K, Wolfe F. Comorbid depression is an independent risk factor for mortality in patients with rheumatoid arthritis. J Rheumatol. 2005;32(6):1013-1019.
27. Antelman G, Kaaya S, Wei R, et al. Depressive symptoms increase risk of HIV disease progression and mortality among women in Tanzania. J Acquir Immune Defic Syndr. 2007;44(4):470-477.

28. Fan VS, Ramsey SD, Giardino ND, et al.; National Emphysema Treatment Trial (NETT) Research Group. Sex, depression, and risk of hospitalization and mortality in chronic obstructive pulmonary disease. Arch Intern Med. 2007;167(21):2345-2353.

29. Onitilo AA, Nietert PJ, Egede LE. Effect of depression on all-cause mortality in adults with cancer and differential effects by cancer site. Gen Hosp Psychiatry. 2006;28(5):396-402.

30. Mykletun A, Bjerkeset O, Dewey M, Prince M, Overland S, Stewart R. Anxiety, depression, and cause-specific mortality: the HUNT study. Psychosom Med. 2007;69(4):323-331.

31. Gallo JJ, Bogner HR, Morales KH, Post EP, Lin JY, Bruce ML. The effect of a primary care practice-based depression intervention on mortality in older adults: a randomized trial. Ann Intern Med. 2007;146(10):689-698

32. Miller GE, Freedland KE, Duntley S, Carney RM. Relation of depressive symptoms to C-reactive protein and pathogen burden (cytomeg alovirus, herpes simplex virus, Epstein-Barr virus) in patients with earlier acute coronary syndromes. Am J Cardiol. 2005;95(3):317-321.

33. Schram MT, Euser SM, de Craen AJ, et al. Systemic markers of inflammation and cognitive decline in old age. J Am Geriatr Soc. 2007;55(5):708-716.

34. Carney RM, Blumenthal JA, Freedland KE, et al. Low heart rate variability and the effect of depression on post-myocardial infarction mortality. Arch Intern Med. 2005;165(13):1486-1491.

35. Hill Golden S. A review of the evidence for a neuroendocrine link between stress, depression and diabetes mellitus. Curr Diabetes Rev. 2007;3(4):252-259. 